\title{
Methodology of Product Sustainable Redesign. Case Study: Furniture of a Clothing Retail Store
}

\author{
Natalia Muñoz López ${ }^{(凶)}$, José Luis Santolaya Sáenz, and Anna Biedermann \\ Department of Design and Manufacturing Engineering, University of Zaragoza, \\ María de Luna 3, 50018 Zaragoza, Spain \\ nataliam@unizar.es
}

\begin{abstract}
Companies awareness of the impact generated by its products increases and motivates them to develop initiatives to improve their sustainability. In this work, a methodology consisting of three main phases: sustainability assessment, redesign process and comparison of designs, is proposed to obtain more sustainable product designs. Methodology is based on the Life Cycle Sustainability Assessment (LCSA) approach, which is applied to simultaneously evaluate environmental, economic and social aspects. In the case study the sustainability improvement of the furniture of a clothing retail store is addressed. A set of indicators are considered to evaluate the sustainability performance of both initial design and redesign. The study concludes that the application of different sustainability strategies allows a significant enhancement of the environmental and economic indicators.
\end{abstract}

Keywords: Sustainable design · Life Cycle Sustainability Assessment ·

Sustainability indicators

\section{Introduction}

Design for sustainability (DfS) has been mainly focused on the integration of environmental aspects into product design (usually referred to as Eco-design). However, sustainability does not only consist of the environmental impact. Three dimensions: environment (planet), economy (profit) and social well-being (people) should be taken into account according to a worldwide approach [1,2] and should be simultaneously analyzed to effectively achieve sustainability assessment. Consistent with this perspective, the Life Cycle Sustainability Assessment (LCSA) methodology [3-5] was developed based on the same structure already established in Life Cycle Assessment (LCA) method $[6,7]$.

On the other hand, eco-design studies [8] are generally aimed at comparing different stages of the entire life cycle of a product, comparing impacts of different alternatives and evaluating impacts in order to propose improved alternatives. Studies which include a new sustainable product redesign, its sustainability assessment and a comparison with the initial design, are usually not carried out. 
In this work, a practical scheme to project more sustainable products considering environmental, economic and social aspects is proposed and applied in the case of the furniture used in a clothing retail store. A redesign phase, in which sustainability strategies consistent with the initial product specifications like operation or appearance, is addressed. In addition, indicators of each sustainability dimension are compared to detect improvements. The methodology applied and results obtained are shown in the following sections.

\section{Methodology}

A methodology composed of three main phases is proposed to achieve more sustainable design [9] (Fig. 1):

- Phase 1- Sustainability of the initial design is assessed according to LCSA approach. Environmental impacts, economic aspects and social issues are obtained compiling inputs and outputs of the system object of study and evaluating a set of suitable indicators.

- Phase 2- Redesign process is carried out incorporating sustainability aspects. Several sustainability strategies can be proposed according to the Life Cycle Design Strategy (LiDS) wheel [10]. A new inventory of the production stage relative to the new product design is performed and the sustainability indicators associated with the redesign are quantified.

- Phase 3- Comparing designs. The sustainability of both initial design and redesign is compared through environmental, economic and social indicators. To interpret the results obtained associated with the redesign and to know if a sustainability improvement has been reached, a parallel representation of indicators [5] is chosen instead of a sustainability aggregated index.

In this work, furniture used in a clothing retail store is the system analyzed and the product creation stage is the object of study. To value social issues, UNEP's guidelines [11] were used. The environmental dimension is evaluated by the Global Warming Potential $\left(\mathrm{GWP}_{100}\right)$ indicator, which represents total emissions of the greenhouse gases calculating the radiative forcing over a time horizon of 100 years. For the economic dimension, the budget of material execution (BME) that expresses the total cost to develop each piece of furniture is the indicator proposed. Finally, workers are selected to analyze the social dimension of sustainability and the indicator used is the time required by the workers in the production process $\left(\mathrm{T}_{\mathrm{W}}\right)$.

The environmental module of Cype software, Probas database [12] and emission factors of electric commercial companies were used to calculate sustainability indicators. 


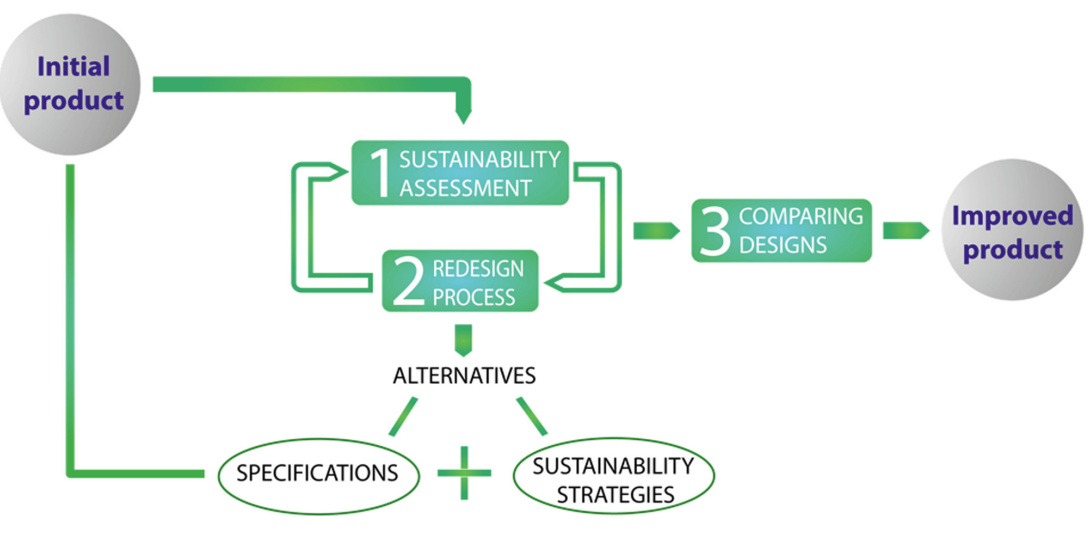

Fig. 1. Phases of a redesign of more sustainable products.

\section{Case Study}

The methodology was applied to design more sustainable furniture, which is used in a clothing retail store located in the centre of a big city. As is shown in Fig. 2, a set of furniture pieces is needed to obtain a good arrangement and exhibition of the selling items: three glass and two chipboard shelves on the store sidelines and other in the storefront to hang and expose clothes, a set of bars to show accessories, a central table to put down the tried clothes by the customers and where the shop assistants blend it and finally, two exhibitor furniture to expose costume jewelry, charge and packaging the sold items.

Furniture pieces:
(1) Accesories bar
(2) Warehouse ledge
(3) Chipboard shelf
(4) Glass shelf
(5) Exhibitor furnit.
(6) Central table
(7) Storefront furnit.
(8) Ground level shelf

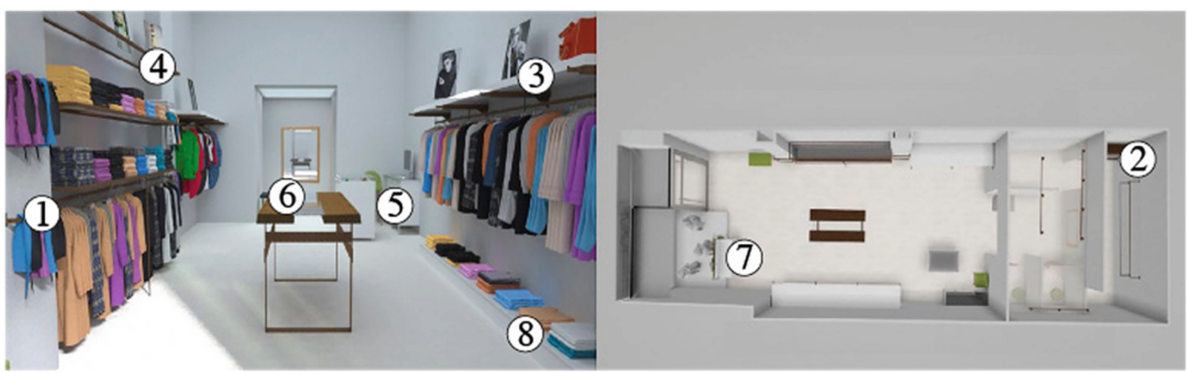

Fig. 2. Furniture pieces.

The production process of the furniture pieces is analyzed in detail to obtain energy consumptions, economic costs and working times. Materials used are laminated chipboard, walnut wood, templated glass and corten steel ASTM A588, which is acquired in boards, sheets and profiles of different sizes. 
The following inventory data, in reference to one unit of the furniture piece, are shown in Table 1: quantity, mass and material type used by each piece, energy consumption, working time needed in processing and production total costs. If the furniture piece of 3. Chipboard shelf is reviewed, we can observe that 2 units are used at the clothing store, which has a mass of $68,7 \mathrm{~kg}$ each one, the materials used to fabricate them are laminated chipboard and corten steel ASTM A388, an energy consumption of 0,37 MJ is required in processing, the working time is $125,6 \mathrm{~s}$ and the production costs are 182,7 $€$. Sustainability indicators of the initial design were calculated. Greenhouse emissions of $494,4 \mathrm{KgCO}_{2} \mathrm{eq}$, a total execution cost of $2153,4 €$ and an average working time of $2,1 \mathrm{~h}$ were obtained. These indicators will be compared with those obtained after the redesign process in Fig. 3.

Table 1. Furniture production stage inventory.

\begin{tabular}{|c|c|c|c|c|c|c|}
\hline \multirow[t]{2}{*}{ Furniture piece type } & \multirow{2}{*}{ Units } & \multirow[t]{2}{*}{ Mass (kg) } & \multirow{2}{*}{$\begin{array}{l}\text { Material } \\
\text { type }\end{array}$} & \multicolumn{2}{|l|}{ Processing } & \multirow{2}{*}{$\begin{array}{l}\mathrm{BME} \\
(€)\end{array}$} \\
\hline & & & & Energy (MJ) & $\begin{array}{l}\mathrm{Tw} \\
(\mathrm{s})\end{array}$ & \\
\hline 1. Accessories bar & 5 & 1,2 & ASTM A588 & 0,05 & 56,9 & 4,8 \\
\hline 2. Warehouse ledge & 4 & 3,8 & Walnut wood & 0,07 & 14,7 & 69,5 \\
\hline 3. Chipboard shelf & 2 & 68,7 & $\begin{array}{l}\text { Lam. chipboard } \\
\text { ASTM A588 }\end{array}$ & 0,37 & 125,6 & 182,7 \\
\hline 4. Glass shelf & 3 & 29,7 & $\begin{array}{l}\text { ASTM A588 } \\
\text { Templat. glass }\end{array}$ & 0,11 & 53,3 & 151,5 \\
\hline 5. Exhibitor furnit. & 2 & 66,2 & $\begin{array}{l}\text { Lam.chipboard } \\
\text { A1 6061A } \\
\text { Templat. glass }\end{array}$ & 4,94 & 2741,3 & 199,1 \\
\hline 6. Central table & 1 & 58,2 & $\begin{array}{l}\text { Walnut wood } \\
\text { ASTM A588 } \\
\text { Templat. glass }\end{array}$ & 0,38 & 198,3 & 422,2 \\
\hline 7. Storefront furnit. & 1 & 92,9 & $\begin{array}{l}\text { Lam. chipboard } \\
\text { ASTM A588 }\end{array}$ & 0,86 & 985,6 & 121,1 \\
\hline $\begin{array}{l}\text { 8. Ground level } \\
\text { shelf }\end{array}$ & 1 & 33,4 & Lam. chipboard & 0,46 & 223,2 & 89,7 \\
\hline
\end{tabular}

The next phase consists of the furniture redesign process having into account the specifications of the initial design, keeping the store esthetics unchanged and to guaranty the storing and display of the clothes. Concerning the production stage, the strategies of materials quantity reduction, replacement or elimination of elements and selection of low-impact materials are considered suitable to achieve a sustainability improvement.

Table 2 shows the initial design and the redesign of the furniture pieces 3, 5, 7 and 8. Different sustainability strategies are applied in each case preserving initial design 
specifications. The production process of the redesigned furniture pieces is analyzed taking into account these strategies and energy consumptions, economic costs and working times are obtained for the new design projected. As is shown in Table 2, significant improvements of the mass of the raw material and thus, in $\mathrm{GWP}_{100}$ indicator, are obtained. At the same time, emissions, working times and costs can be reduced in the production process. In all cases, the percentage reduction of indicators according to the sustainability strategies applied, are indicated.

Table 2. Redesign of furniture pieces.

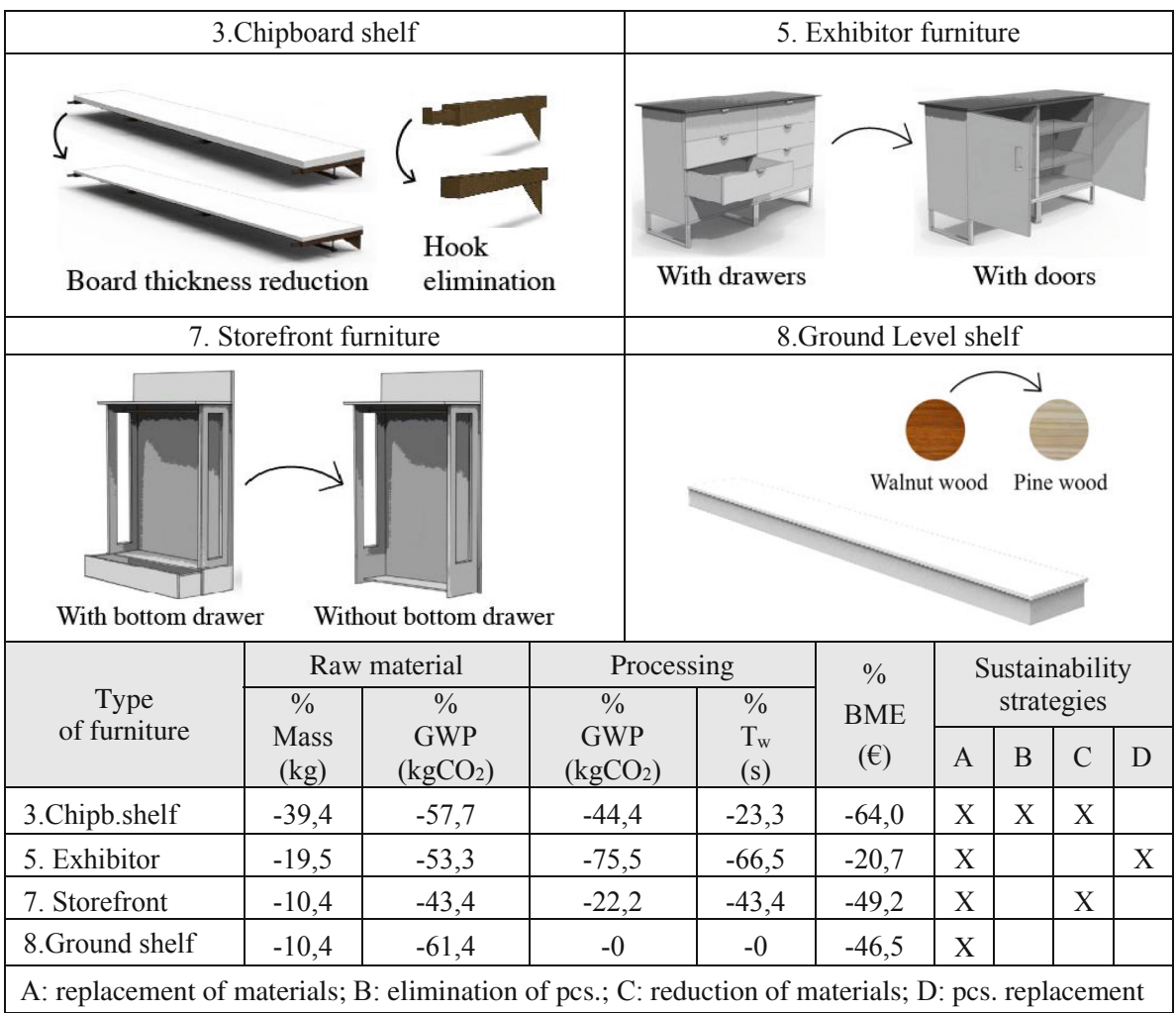

Finally, the third phase of redesign methodology is carried out. A comparison between the environmental, economic and social indicators of the furniture initial pieces and its redesign are shown in Fig. 3. An improvement of the sustainability indicators is achieved. A reduction of $40 \%$ and $20 \%$ is reached in the environmental and economic indicators respectively. The working time is decreased in $1,15 \mathrm{~h}$. 

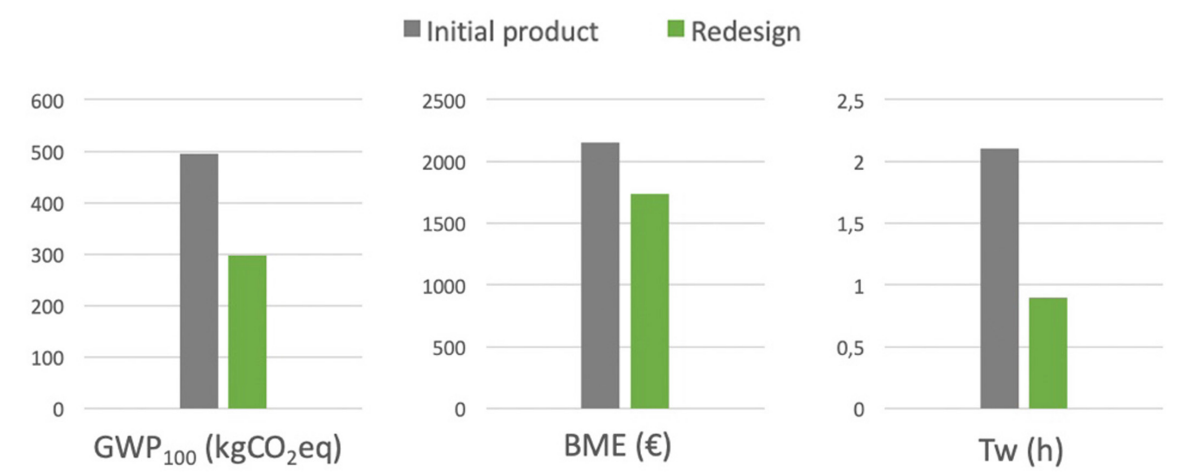

Fig. 3. Sustainability indicators comparison

\section{Conclusions}

This work presents a redesign methodology to achieve more sustainable products. Three phases are carried out: sustainability assessment, redesign process and comparing designs. A set of suitable indicators was selected to simultaneously assess the three sustainability dimensions and to compare initial and final designs.

The redesign of furniture used in a clothing retail store was performed. A production inventory was obtained by means of a detailed study of each furniture piece. Data of materials, energy consumptions, production costs and working times were calculated in both initial design and projected redesign of furniture. The early specifications of each furniture piece like operation and appearance were taken into account in the redesign process.

A substantial improvement of the furniture sustainability indicators at the production stage was managed by the application of different sustainability strategies. Particularly, the use of pine wood and the pieces' elimination were the most effective strategies.

A significant enhancement of greenhouse emissions and processing costs and a slight improvement in the working times was achieved.

\section{References}

1. WCED (World Commission on Environment and Development): Our common future. Oxford University Press (1987)

2. UNCED Agenda 21: The Rio Declaration on Environment and Development. United Nations Conference on Environment and Development, Rio de Janeiro (1992)

3. Kloepffer, W.: Life-cycle based sustainability assessments as part of LCM. In: Proceedings of the 3rd International Conference on Life Cycle Management, Zurich (2007)

4. Finkbeiner, M., Schau, E.M., Lehmann, A., Traverso, M.: Towards life cycle sustainability assessment. Sustainability 2(10), 3309-3322 (2010)

5. Valdivia, S., Ugaya, C.M.L., Hildenbrand, J., Traverso, M., Mazijn, B., Sonneman, G.: A UNEP/SETAC approach towards a life cycle sustainability assessment-our contribution to Rio+20. Int. J. Cycle Assess. 18, 1673-1685 (2013) 
6. ISO: ISO 14040 International Standard. Environmental management - Life cycle assessment - Principles and framework. International Organisation, Geneva, Switzerland, (2006a).

7. ISO: ISO 14040 International Standard. In: Environmental management - Life cycle assessment - Requirements and Guidelines. International Organisation, Geneva, Switzerland (2006b)

8. Lacasa, E., Santolaya, J.L., Biedermann, A.: Obtaining sustainable production from the product design analysis. J. Clean. Prod. 139, 706-716 (2016)

9. Santolaya, J.L., Lacasa, E., Biedermann, A., Muñoz, N.: A practical methodology to project the design of more sustainable products in the production stage. Res. Eng. Des. 30, 539-558 (2019)

10. Brezet, J.C., Van Hemel, C.G.: Eco-design: A Promising Approach to Sustainable Production and Consumption. UNEP. United Nations Publications, Paris (1997)

11. UNEP/SETAC: Guidelines for Social Life Cycle Assessment of Products. United Nations Environment Programme, Paris (2009)

12. UBA: Umweltbundesamt (UBA). German Environmental Protection Agency (2007)

Open Access This chapter is licensed under the terms of the Creative Commons Attribution 4.0 International License (http://creativecommons.org/licenses/by/4.0/), which permits use, sharing, adaptation, distribution and reproduction in any medium or format, as long as you give appropriate credit to the original author(s) and the source, provide a link to the Creative Commons license and indicate if changes were made.

The images or other third party material in this chapter are included in the chapter's Creative Commons license, unless indicated otherwise in a credit line to the material. If material is not included in the chapter's Creative Commons license and your intended use is not permitted by statutory regulation or exceeds the permitted use, you will need to obtain permission directly from the copyright holder.

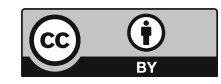

